\title{
LOGÍSTICA NA CADEIA DE SUPRIMENTOS
}

\author{
https://dx.doi.org/10.48097/2674-8673.2021n4p11
}

\author{
Adeilton José dos Santos ${ }^{1}$ \\ Susymary leitão ${ }^{2}$
}

\begin{abstract}
RESUMO
O presente artigo visa analisar como é o processo de suprimentos em uma empresa multinacional de produtos químicos, tratando especificamente do processo de prestação de serviço e aquisição de materiais. O estudo buscou analisar a cadeia de suprimentos, estabelecendo o relacionamento da empresa Manuchar com outras empresas, na procura de enfatizar sua importância competitiva em ambientes empresariais e, além disso, elevar o nível de serviços aos clientes. A pesquisa buscou validar os resultados por meio da interação entre aspectos teóricos e o posicionamento da empresa frente aos elementos centrais da logística de suprimentos.
\end{abstract}

Palavras-chave: Logística. Cadeia de suprimentos. Distribuição.

\begin{abstract}
This article aims to analyze what the supply process is like in a multinational chemical company, dealing specifically with the service provision and material acquisition process. The study sought to analyze the supply chain, establishing the relationship of the company Manuchar with other companies in an attempt to emphasize its competitive importance in business environments. In addition, raise the level of services to customers. The research sought to validate the results through the interaction between theoretical aspects and the company's position in relation to the central elements of supply logistics.
\end{abstract}

Keywords: Logistics. Supply chain. Distribution.

Data de submissão: 07/10/2020

Data de aprovação: 11/11/2020

\section{INTRODUÇÃO}

O tema escolhido para a apresentação desse artigo deve-se ao interesse sobre o assunto, e também pela experiência de trabalho em um centro de distribuição. Diante da necessidade de uma boa logística na cadeia de suprimentos, fica evidente a satisfação de escrever sobre

1 Discente do Curso Tecnológico de Logística da FMGR. E-mail: adeilton.santos20@hotmail.com

2 Professora da FMGR e orientadora do artigo. E-mail: susimary@gmail.com 
esta temática.

A logística abrange processos relativos ao transporte e ao armazenamento de mercadorias, matérias-primas e insumos. É importante garantir que o bem ou produto vá do fornecedor à empresa, e da empresa para o consumidor final com rapidez, segurança e baixos custos, mas levando em conta as necessidades internas da organização.

$\mathrm{Na}$ empresa em destaque, o foco é acompanhar o processo do setor de suprimentos, analisando como são mantidas as relações com indústrias químicas e aquisição de mercadorias.

Sabendo dessa realidade, fica claro que a organização ou qualquer área que trabalhe com esse tipo de segmento tem que dar uma atenção especial ao tema. A logística de suprimentos será de grande importância para o melhor funcionamento da organização.

\section{REFERENCIAL TEÓRICO}

A logística envolve a gestão de processamento de pedidos, estoques, transportes e a combinação de armazenamento, manuseio de materiais de embalagem, todos integrados por uma rede de instalações. Seu objetivo é apoiar as necessidades operacionais de suprimento, manufatura e atendimento ao cliente na cadeia de suprimentos. Dentro de uma empresa o desafio é coordenar a competência funcional em uma cadeia de suprimentos voltada para o serviço aos clientes.

A gestão logística empresarial passou a ser chamada de cadeia de suprimentos, sendo utilizada também como redes de valor, cadeia de abastecimento e corrente de valor. Todos esses termos se designam para um conjunto de atividades que se repetem inúmeras vezes ao passo que as matérias-primas vão sendo convertidas em produtos acabados.

A logística refere-se à responsabilidade de projetar e administrar sistemas para controlar o transporte e a localização geográfica dos estoques de matérias-primas, de produtos em processo e acabados pelo menor custo total. Alcançar o menor custo total significa que os ativos financeiros e humanos aplicados na logística devem ser mínimos.

Cadeia de abastecimento, segundo Ballou (2006), corresponde ao processo para obter materiais, agregar valor de acordo com o desejo do cliente e consumidor e disponibilizar os produtos para o lugar (onde) e para a data (quando) que o cliente e consumidor desejar. Além de ser um processo bastante extenso, a cadeia apresenta modelos que variam de acordo com as características do negócio, do produto e das estratégias utilizadas.

É por meio do processo logístico que a matéria-prima chega até a capacidade produtiva 
de uma nação industrializada e os produtos acabados são distribuídos aos consumidores.

\section{FUNCIONAMENTO DA LOGÍSTICA}

No contexto da cadeia de suprimentos, a logística existe para transportar e posicionar estoques com o objetivo de conquistar benefícios relacionados ao tempo, ao local e à propriedade desejada pelo menor custo.

De acordo com Ballou (1993), a logística estuda como a administração pode prover melhor nível de rentabilidade nos serviços de distribuição aos clientes e consumidores, através de planejamento, organização e controles efetivos para as atividades de movimentação e armazenagem que visam facilitar o fluxo de produtos.

Apesar das elevadas despesas com a logística seu ponto empolgante não é o refreamento ou a redução de custos. A empolgação vem em entender de que modo as empresas usam a competência logística para ajudar a obter vantagens competitivas. Empresas que têm uma competência logística de alto nível conquistam vantagens competitivas como resultado ao fornecer um serviço superior aos seus clientes mais importantes.

\section{Gestão de estoque}

Na gestão de estoque devemos ser o mais eficiente possível, avaliando de forma sucinta as ferramentas de auxílio de tomada de decisão, a fim de obter o máximo de eficiência e lucro necessário, tendo o equilíbrio entre a oferta e demanda.

De acordo com Wanke (2003), a gestão de estoque engloba todo um processo de decisões que envolvem tempo e espaço, verificando a demanda de produtos de forma que sejam atingidos os objetivos de custos e serviços.

No gerenciamento do estoque o responsável tem que se ater a três pontos: quanto pedir, como pedir, e como ajustar o sistema para quais dias serão colocados os pedidos. Desta forma, com os processos definidos, fica bem mais fácil a organização do setor.

Conforme a linha de raciocínio de Bowersox \& Colss:

Controle de estoques é um procedimento rotineiro necessário ao cumprimento de uma política de estoques. O controle abrange as quantidades disponíveis numa determinada localização e acompanha suas variações ao longo do tempo. Essas funções podem ser desempenhadas manualmente ou por computador. As 
principais diferenças são a velocidade, a precisão e o custo. (BOWERSOX; COLSS, 2010, p. 255).

$\mathrm{Na}$ armazenagem podemos definir locação por endereço ou código específico: rua, letra ou a que seja melhor para cada segmento, mas nunca deixar de definir um local específico para que todos tenham acesso ao local de armazenagem. Assim, fica muito mais fácil achar cada item dentro de um estoque. Sempre que for realocar ou tirar algum item do almoxarifado, deve-se utilizar o sistema descrito por Carvalho \& Macedo:

Devem ser implantados sistemas FIFO (First In First Out) ou FEFO (First Expired First Out), "Primeiro que entra primeiro que Sai" ou "Primeiro que Vence Primeiro que Sai". O controle de entrada e saída deve ser feito por meio de programas de informação validados, que permitam a emissão de relatórios periódicos. (CARVALHO; MACEDO, 2010, p. 59).

\section{Cadeia de suprimentos}

De acordo com Silva (2017), a cadeia de suprimentos surgiu com o propósito de integrar todas essas atividades em um processo contínuo, incluindo todas as organizações parceiras na cadeia e os parceiros externos como fornecedores, transportadoras, empresas terceirizadas e prestadores de sistemas de informação, juntando os processos necessários para criar, aprovisionar e realizar entregas conforme as demandas, inserindo a tecnologia para coletar informações sobre as reivindicações do mercado, além da permuta de informações entre as empresas. $\mathrm{Na}$ cadeia de suprimentos todos os procedimentos devem ser vistos como um sistema, sendo que o desempenho de cada integrante influi no desempenho global da cadeia.

A redução dos custos ao longo das cadeias de suprimento pode ocorrer por meio de sistemas de logística reversa e melhoria nas tecnologias de transporte e armazenamento, e também por meio de investimentos pesados em diversas tecnologias inovadoras disponíveis no setor.

\section{METODOLOGIA}

O presente artigo foi realizado com base em pesquisa bibliográfica com o objetivo de adquirir conhecimentos voltados para a área de suprimentos e aquisição de materiais. Este trabalho também contou com o método do estudo de caso, utilizado para a realização desta pesquisa. 
Pode-se dizer que este artigo se enquadra no tipo de estudo exploratório, por ter a intenção de familiarizar-se com o dia a dia do setor de suprimentos e tornar-se bastante flexível por considerar as hipóteses e problemas que possam ocorrer.

\section{DESENVOLVIMENTO DA PESQUISA DE CAMPO}

A pesquisa foi elaborada na empresa Manuchar. Algumas informações foram fornecidas por funcionários, outras foram retiradas diretamente do site da organização. A Manuchar, hoje, é uma das empresas mais bem conceituadas para trading e distribuição de produtos químicos, fertilizantes, produtos minerais e siderúrgicos.

As bases operacionais estão localizadas estrategicamente em cidades portuárias, otimizando a logística e oferecendo, sempre, a melhor solução. Em Pernambuco, a empresa possui três bases operacionais. A base escolhida para o presente artigo foi a do porto do Recife, armazém destinado para granel.

De acordo com as informações fornecidas pelos funcionários, a matéria-prima chega em forma de granel e em seguida passa por processos de conferência, estocagem e distribuição. Existem várias empresas que são clientes da Manuchar, tais como: UNILEVER, CBB e ASA, todas no segmento logístico.

\section{Conferência de mercadoria}

A conferência permite que o funcionário tenha a certeza que a quantidade de itens da nota fiscal esteja de acordo com o que foi recebido fisicamente. O conferente que recebe a mercadoria deve digitar a quantidade de itens que está recebendo e, se houver divergências, deverá passar por uma liberação de inconsistências, permitindo ao responsável tomar a decisão de acatar ou devolver a mercadoria. Somente se liberado ou se consistente o armazenamento da mercadoria será realizado.

Boa parte dos funcionários da Manuchar tem conhecimento em relação ao procedimento de conferência de mercadoria. Eles apontam que é importante que todos saibam, pois a falta do conferente oficial pode ser suprida por outro funcionário.

\section{Estocagem}

Devemos levar em consideração o estoque mínimo ou estoque de segurança. É uma quantidade mínima que devemos deixar disponível por eventuais atrasos de 
transportadoras ou demora de atendimento do fornecedor, garantindo que não haverá falta. Desta forma, haverá uma margem de erro para possíveis imprevistos, otimizando os problemas que são gerados pela falta de estoque mínimo.

\section{Distribuição}

A logística de distribuição compreende as atividades de definição e gestão dos canais mais adequados de venda, comercialização de produtos e prestação de serviços, além das estratégias de suporte a estes processos. Nesse contexto, a Manuchar procura sempre priorizar as atividades de gestão de transporte, administração de frete e roteirização para a melhor prestação de serviço para os seus clientes.

\section{CONSIDERAÇÕES FINAIS}

A logística na cadeia de suprimentos apresenta-se como um organizador do fluxo logístico empresarial. Entre suas funções salienta-se a alavancagem do posicionamento estratégico, podendo, portanto, apresentar uma vantagem competitiva empresarial.

A empresa analisada em Recife-PE tem uma gestão logística que visa à redução de custos e uma maior flexibilização no atendimento ao cliente. As atividades da empresa, como recebimento, estocagem e distribuição de produtos são de suma importância para seu sucesso. O responsável pelo gerenciamento deve tomar as decisões precisas para evitar desperdícios e rentabilizar resultados que possam proporcionar lucro para a empresa.

A principal limitação da pesquisa está no próprio método utilizado no estudo de caso. Este estudo retrata uma realidade específica que pode ser ou não aplicada em outras organizações.

Tendo o conhecimento que foi mencionado neste artigo, fica evidenciado a importância do mesmo. A pesquisa mostra o quão importante é a logística na cadeia de suprimentos.

Como sugestão, os pesquisadores podem aprofundar-se neste assunto, ajudando a contribuir na otimização dos artigos e economizando não só tempo, mas dinheiro, permitindo que todos os interessados possam ter acesso a esta pesquisa. 


\section{REFERÊNCIAS}

BALLOU, Ronald H. Logística empresarial. São Paulo: Atlas, 1993.

BALLOU, Ronald H. Genrenciamento da cadeia de suprimentos/Logística Empresarial. 4. ed. Porto alegre: Bookman, 2006.

BOWERSOX, Donald J.; CLOSS, David J.; COOPER, M. Bixby; BOWERSOX, John C. Gestão Logística da Cadeia de Suprimentos. 4 ed. São Paulo: McGraw Hill, 2014.

CARVAlHO, S.; MACEDO, S. Logística Farmacêutica Comentada. São Paulo: Medfarma, 2010.

FONSECA, José Saraiva. Metodologia de pesquisa científica. Sobral: INTA, 2017.

MANUCHAR. Disponível em: www.manuchar.com.br. Acesso em: 17 set. 2020.

POZO, H. Administração de Recursos Materiais e Patrimoniais. 6. ed. São Paulo: Atlas,2010.

SILVA, Leandro Aparecido da. Cadeia de suprimentos: definição, história, perspectivas, características e desempenho. 03 de Fevereiro de 2017. Disponível em: http://www.administradores.com.br/artigos/academico/cadeia-de-suprimentosdefinicaohistoria-perspectivas-caracteristicas-e-desempenho/102314/. Acesso em: 16 ago. 2020.

SILVA, Bráulio Wilker. Gestão de estoques: planejamento, execução e controle. 2. ed. João Monlevade: BWS Consultoria, 2019.

WANKE, P. Gestão de estoques na cadeia de suprimento. São Paulo: Atlas, 2003. 